\title{
Article
}

\section{Research ethics in practice: Lessons from studies exploring intimate partner violence in different contexts}

Vearey, J, Barter, Christine Anne, Hynes, P and McGinn, A Available at http://clok.uclan.ac.uk/14739/

Vearey, J, Barter, Christine Anne ORCID: 0000-0001-5682-5333, Hynes, P and McGinn, A (2017) Research ethics in practice: Lessons from studies exploring intimate partner violence in different contexts. Families, Relationships and Societies, 6 (2). pp. 273-289. ISSN 2046-7435

It is advisable to refer to the publisher's version if you intend to cite from the work. http://dx.doi.org/10.1332/204674316X14673790283737

For more information about UCLan's research in this area go to http://www.uclan.ac.uk/researchgroups/ and search for <name of research Group>.

For information about Research generally at UCLan please go to http://www.uclan.ac.uk/research/

All outputs in CLoK are protected by Intellectual Property Rights law, including Copyright law. Copyright, IPR and Moral Rights for the works on this site are retained by the individual authors and/or other copyright owners. Terms and conditions for use of this material are defined in the policies page. 


\title{
Research ethics in practice: lessons from studies exploring interpersonal violence in different contexts
}

\begin{abstract}
Studies researching interpersonal violence (IPV) are associated with a range of ethical challenges. In this paper, lessons are drawn from three case studies exploring the experiences of different groups of survivors and perpetrators of IPV in diverse contexts: refugees in the Thailand-Burma border area; partner-violent adult men and female survivors in Ireland; and, school children in five European countries. The ethical - and associated methodological - challenges faced, and the ways in which they were overcome, are presented. Drawing on the case studies presented, the paper concludes that three key areas require special attention when conducting research in this field: accessing and recruiting participants, researcher skills and experience, and appropriate use of data.
\end{abstract}

\section{Introduction}

Studies researching interpersonal violence (IPV) ${ }^{1}$ are associated with a range of ethical, and associated methodological, challenges (Fontes, 2004). This includes concerns - both practical and theoretical - relating to notions of 'vulnerability' and the provision of informed consent, confidentiality, and participation (Hurst 2008; Lott, 2005). To explore these ethical challenges, this paper is divided into two sections. The first section draws lessons from three studies exploring the experiences of different groups of survivors and perpetrators of IPV in diverse contexts: refugees in the Thailand-Burma border area; partner-violent adult men and female survivors in Ireland; and, school children in five European countries. The ethical challenges faced, and the ways in which they were overcome, are presented. The second part of the paper discusses three key areas that, we argue, require special attention when conducting research with survivors and perpetrators of IPV, namely: skills of the research team; ways of accessing and recruiting participants; and, the appropriate use of data. By reflecting on the case studies presented, it is clear that both benefits and risks to participants are associated with research involving survivors and perpetrators of IPV. We argue that researchers investigating IPV have an ethical responsibility both to protect participants, and to ensure that their research will generate new knowledge to affect positive change. The case studies presented highlight the ways in which research can benefit participants through the development of context-specific, ethical responses.

\section{Three case studies}

\section{Case study 1: The Thailand-Burma border}

In recent years, there has been an increase in 'rights work' in refugee camps and humanitarian contexts focussing on "rights primarily breached in private, by husbands or other males" (Hilhorst and Jansen, 2012, p901). In conflict-affected areas and any consequent humanitarian context, the ability to carry out ethically conducted research into sexual ${ }^{2}$ and gender based violence is difficult, logistically challenging and complex. Given the sensitivities of such research and the potentially

\footnotetext{
1 'Interpersonal violence' has been defined by the WHO as 'violence that occurs between family members, intimate partners, friends, acquaintances and strangers, and includes child maltreatment, youth violence (including that associated with gangs), violence against women (for example, intimate partner violence and sexual violence) and elder abuse.' (Krug et al., 2002)

2 'Sexual violence' as defined by the WHO: '... any sexual act, attempt to obtain a sexual act, unwanted sexual comments or advances, or acts to traffic, or otherwise directed against a person's sexuality using coercion, by any person regardless of their relationship to the victim, in any setting including but not limited to home and work.' (WHO, 2010)
} 
stigmatising impact of being identified as a survivor or IPV, use of the data generated can be problematic if not carefully managed. This includes considerations relating to maintain confidentiality, including anonymising locations and descriptions thereof when reporting findings.

To discuss this, three real-life, anonymised examples are outlined - selected to highlight ethical challenges in the 'field'. The 'field' in this instance refers to the humanitarian context along the Thailand-Burma border. The examples occurred more than 15 years ago (between 1996 and 2000) and have not previously been outlined for publication purposes; this time lapse assisting with issues around anonymity and confidentiality outlined below. Each of the examples were the result of ongoing qualitative research with in-depth interviews as the core method alongside observation. During this period, examples such as these were not "extreme" examples; rather they were "typical" (Esterhuizen, 2004: 22) examples of an environment of collective violence ${ }^{3}$ encountered by women along this border.

Example A: Ten ethnic Karen women and two Karen men had been arrested inside Burma whilst tending their paddy fields in a location approximately two hours away from the Thailand-Burma border. The two men had their hands tied behind their backs, were kicked, beaten on the back of the neck with guns and sticks and were shot shortly after their arrest. The ten women were taken to a military base and, after 3 or 4 days, two of the older women (55 and 60 years old) were released and walked to Thailand. It was suspected within the refugee camp the women had reached that the remaining women were being held for the daytime purposes of forced labour and night time sexual violence.

Example B: A dry season offensive by the Burmese military resulted in 24 ethnic Karen villages being burned to the ground plus multiple accounts of killings, torture and rape. The numerous accounts of rape included detailed descriptions of the methods used by soldiers. These descriptions included women being raped in front of their tied up husbands, fathers and sons; women being continuously raped by battalions of soldiers over two days; pregnant women being raped; and women being taken to military bases. Accounts provided by those arriving by foot into Thailand detailed names and ages of the women involved and detailed descriptions of family composition.

Example C: The camp leader of a refugee camp for ethnic Mon, Tavoyan and Karen refugees from Burma, in a refugee camp in Thailand, was asked to provide women to the local security to "cook" and "clean". The leader was asked for a woman from each section of the camp and sent women who were older than 40 years old. These women were sent back and the leader was told that they were not to send older women for this work - rather, younger and unmarried women were required. One section leader refused and went into hiding; three other sections leaders sent women. Reports emerged that the young women were being paid "to stay with them until midnight and sometimes the whole night". Witnesses also described how the women "have to cook, pour drinks and be grabbed and kissed" and that they had "no choice". The local security drank heavily each day and acts of violence against men and women were frequently recounted.

\section{Gathering data with difficult-to reach populations}

In each of these examples, detailed data collection would be ethically difficult, if not impossible. In contexts where detailed demographic data collection poses challenges, the sensitivities of conducting research on sexual or gender based violence are great. In Example A, given lack of access in Burma to researchers, the UN, international NGOs or other agencies, the remaining eight women held in the military base were completely inaccessible. In Example B, detailed accounts of this collective violence provided by male and female witnesses contained contradictory information. In Example C, political

\footnotetext{
3 'Collective violence' has been defined by the WHO as: 'Instrumental violence inflicted by larger groups such as nation states, militia groups and terrorist organisations in order to achieve political, economic or social objectives.' (Krug et al., 2002)
} 
sensitivities around hosting refugees and the dangers of interference in national security arrangements for refugees might effectively mute researchers and agencies involved from public action.

Barriers to disclosing abuse and/or exploitation were considerable. In Example A, social norms placing shame on individuals subject to sexual violence and, at a community level, support notions of sexual chastity for women were predominant, with virginity an expectation for marriage. The two older women who were released did not wish to provide details of what they had witnessed in case the remaining women were stigmatised or ostracised by other members of the refugee camp. In Example B, contradictory information about individual cases may have been about the preservation of dignity or as a result of the many traumatic encounters experienced. It was, however, clear that there was on-going collective violence and the individuals affected were unreachable, in critical conditions, or had died. In Example C, the likelihood of young women disclosing abuse in a context where the security of others was at stake - including family members in the refugee camp - was minimal.

\section{Logistical, gatekeeper and interpretation challenges}

Research in this area is logistically challenging. Populations involved may be in unsafe cross-border situations or contained in refugee camps - spaces that are often isolated geographically, politically, socially and economically. Research, rather than the direct delivery of support and services, may be perceived as low priority in such contexts. Gatekeepers can enable or limit access possibilities, attempt to control research and/or attempt to present themselves in a good light.

The use of interpreters is fraught with potential difficulties. Logistically, finding interpreters who speak English plus the languages and dialects of interviewees will be challenging. Providing training for interpreters is ideal but in contexts of shortage may not be feasible and untrained interpreters may be the only option. Interpreters drawn from the population concerned may also wish to prioritise their own views, and interviewee selection criteria will need to be clear. In contexts of high literacy, the provision of information sheets and 'informed consent' documentation in different languages and dialects is helpful but must be carefully worded to avoid connotations that may harm individuals participating. Pre-literate or oral cultures will require a different approach. Co-production of these with local actors is optimum, as are iterative informed consent processes. Refugees rarely have many rights and may not wish to sign consent forms so these may necessarily be non-obligatory.

For interviews with people who have experienced sexual violence, gender is of course a further consideration. Social norms that prioritise male dominance may mean there are no female interpreters available. The use of male interpreters is of course problematic and data about sexual and gender-based violence and/or how people become vulnerable to trafficking (Hynes, 2010) may be forthcoming from community based organisations but not directly from female interviewees with male interpreters. Further issues around trust and mistrust in humanitarian contexts are also relevant (Hynes, 2003).

In Example A above, only male interpreters were available and it is likely that the contradictions encountered were partly as a result of this. In Example B above, a local female, ethnic Karen interpreter volunteered to provide translation to journalists, NGO staff and researchers. This interpreter spoke fluent English and Karen but during one interview with a newly arrived refugee, discovered that a former school friend had been affected when precise names and details of attacks were being conveyed. Interviews were necessarily terminated at this point and, without any formal counselling or psychosocial support available to any refugees in the camps, the support of a faith-leader and close family members was located. Supporting interpreters with such disclosures are important ethical considerations in themselves. In humanitarian contexts this is difficult to achieve and/or not prioritised due in part to scarce resource. In Example C, a female interpreter from the section of the refugee camp that refused to send women was available but not from the other sections. 


\section{Complexities of confidentiality and anonymity}

In Examples A, B and C above, interviews and discussions about incidents of sexual violence and broader circumstances in refugee camps took place with male camp and section leaders who then provided access to mainly female interviewees. This acceptance of interviews nominated by 'community leaders' is highly problematic (Mackenzie, et al., 2007). In all cases, confidentiality was discussed at length with interpreters prior to interviews taking place. However, the lack of privacy during interviews clearly impacted on both levels of disclosure and the quality of data collected. Conducting interviews in refugee camps in private is rarely possible and options to interview individuals outside camps hampered by travel restrictions. Even after attempts at minimising the numbers of people present, it was not unusual for section leaders, family members and other camp residents to be present and join in during interviews.

Research into the challenges of constructing ethical relations in refugee research outlines how principles of beneficence and the need to move beyond harm minimization as a standard are necessary (Mackenzie, et al., 2007). Reciprocity, co-design and conducting research with rather than on or for refugees is entirely feasible. Along the Thailand-Burma border, documentation and grey literature surrounding sexual and gender-based violence has emerged from a range of agencies and civil society with methodologies that engage local stakeholders with awareness of the context, dangers, complexities and risk of conducting such sensitive research (Apple, 1998; KHRG 2006, 2014; SWAN and SHRF, 2002). With care and appropriate training, engagement of local stakeholders in meaningful ways can enable research to be contextually embedded and allow barriers to conducting research ethically to be overcome. Co-production of research with locally-based civil society organisations can alert researchers to sensitivities involved and training of these same organisations in standard research practice complemented this. Adopting an approach of working 'with', rather than 'on' or 'for' refugees may take longer but may also yield more ethically-sensitive data (Hyne, 2003).

\section{Case study 2: Research with survivors and perpetrators of partner-violence in Ireland}

This case study reflects on the ethical issues involved in conducting a study of change processes in partner violent men; the 'change in partner-violent men study'. Building on findings from a series of systematic reviews of qualitative studies in this area (see McGinn, Taylor, McColgan and McQuilkan, 2014; McGinn, Taylor, McColgan and Lagdon, 2015; McGinn, 2016), a study of partner-violent men in Ireland was undertaken. The study has been described elsewhere (McGinn, Taylor and McColgan 2016) and involved interviews with 18 survivors of IPV and 20 partner-violent men, including four couple dyads. Participants were drawn from IPV perpetrator programmes and survivor support agencies.

\section{Qualitative interviews as a positive intervention}

Believe it or not, it takes more courage sometimes to walk away and that's even after all these years, I'm sitting here, still struggling with that. And I just hope, fingers crossed, that I have the strength to say "you're not doing it again and that's it now. I've had my share." And I'm just keeping my fingers crossed. As a matter of fact, this (this interview) was a good thing, believe it or not, I know I was saying after yesterday (yesterday the study participant and her expartner had agreed to cease contact) but I think this was good for me today.

(A survivor interviewed during the 'change in partner-violent men' study.)

It could be argued that the Rogerian premise applies here: simply allowing someone to talk about their concerns, and having someone listen in a non-judgemental and empathetic way, is in itself therapeutic. Several of the perpetrators interviewed commented on how the interview had refreshed their memory of their intervention content, and their learning from it. Most of the survivors interviewed indicated that they had benefitted from sharing their experiences in the research process, even though they had access to support workers, with whom they had often developed trusting relationships. 
Considering the potential to cause harm

One of the ethics committees, from which approval for the 'change in partner violent men' study was obtained, made it clear that applicants should not cite the therapeutic benefit of qualitative interviews in support of their application, as this has not been sufficiently researched. Further, some commentators have explored the potential for harm to violence survivors, in this type of research, in some detail, and highlight the potential to further traumatise survivors (for example Fontes, 2004; and McCosker, Barnard, \& Gerber, 2001).

Firstly, there is a recognised danger of collaborating, inadvertently, with perpetrators in the cognitive distortions which fuel their violence (Sullivan \& Cain, 2004). Interview data pertaining to how perpetrators felt unfairly treated during a perpetrator programme was highly relevant in this study but the discussions which elicited this data were ethically problematic. The interviewer wanted to hear what the perpetrators had to say, and needed to use effective conversational prompts to help elicit the data needed, but at the same time the interviewer needed to avoid collaborating on the idea that abuse survivors could be partly responsible for the abuse they have suffered. The following data from the study illustrates the challenge the interviewer faced in achieving this balance:

Interviewee - But at the same time, I think that, that being away from the triggers, I mean one of the things that, I learned from the course, is that it is a 50-50 thing, it's certainly not abusive men, it's not just abusive men, and that is what the focus was on, it's not that at all, it's abusive women, that create, and are a part of, I'm not going to say that the women create abusive men, or the men create the women, but certainly the two together create each other.

Researcher $-\mathrm{Mm} \mathrm{mm}$ ? You see there is another, very strong argument out there, that changing someone who has been violent must start with them realising that it does not matter what the other person (the victim) is doing, it is not an option to ... violence is not an option.

Interviewee - and this is what they said (the group facilitators at the perpetrator programme). It is very one sided, from my point of view. In my situation, ... a lot of the rows started, primarily because I wanted to, I wanted to help move on (after a family tragedy) and she wouldn't, you know and then, and then I shouted, and she hid more, I shouted because she hid, she hid more, .. And we would trigger each other off, and this is what I was saying that, that, two people are involved.

I have seen women like to take the complete piss out of guys, I have seen women push guys to see how far they could push them, and then she is surprised when he slaps her?

\section{Researcher - Mmm?}

Interviewee - It's not right, he should never have done that, but where do you draw the line?

In this extract the researcher appears to be aware of IPV perpetrators' tendency toward blaming or rationalising violent behaviour, and he avoids collaborating upon the interviewee's violent world-view. It can be seen that the researcher could easily be side-tracked into challenging the interviewee's interpretation of relationship problems. If this were to happen the interview would become more of a social-work-type exchange, and the possibility of obtaining the interviewee's actual perspective is greatly reduced. It can be seen that the researcher must be able to elicit the interviewee's perspective, while offering no reinforcement of violence-fuelling thinking, while also avoiding a confrontation. There is a need therefore for the interviewer to be familiar with, and to be comfortable working with, IPV perpetrators. In this study, the researcher was able to draw upon his learning from supervised clinical practice, as a child protection worker, working with IPV-affected families.

The researchers also considered qualitative interviews with survivors as a direct risk to survivor safety, and the risk of IPV perpetrators confronting their partners about their participation was acknowledged and explored at length with the ethics committees. 
The recruitment of survivors was handled primarily by their advocacy worker, with whom survivors were already familiar. The advocacy worker presented the opportunity to take part, and discussed it with potential study participants before forwarding the survivor's contact phone number to the researcher. The abuse survivor was in control of the process as far as possible; crucially, it was up to survivors to decide whether or not to tell their (ex-) partner that they were to be involved. In four cases, both the perpetrator and the abuse survivor from the same couple dyad were recruited to the study, but the recruitment processes were kept entirely separate. In these cases it was important that the interviewer did not allow any information to pass through himself, from the perpetrator to the survivor or vice versa. Again, the importance of using an interviewer who has had supervised clinical experience in this field can be seen.

While study participant screening can be the key to the conduct of a safe study, it can also drive recruitment bias. This was recognised during the design of the 'change in partner-violent men' study, and while the researcher was confident that survivors were not putting themselves at further risk by participating in the study, that did not mean that he only interviewed survivors who were at no risk of further abuse. Consider the circumstances of one of the study participants, Jane, which - at the time of the interview- was worrying:

Jane is a mother of two teenage children, is separated from her abusive partner, Peter (her children's father) but lives close to him. Jane has on-going contact with Peter, they see each other approximately once a week. Peter cuts the lawn and takes care of the exterior of Jane's house. Peter has completed a programme of intervention for IPV perpetrators, but has stated that he will not change his behaviour in any way. Jane believes he completed the programme because he was advised to do so by a solicitor. Previously, Peter has been psychologically and physically violent toward Jane. Jane believes Peter has a personality disorder, and will not change, but she feels safe in her current circumstances.

Jane was confident that doing the interview was not adding to her vulnerability, and while Jane's feelings of safety could be misplaced, it was clear that Jane was not being controlled on a day-to-day basis, and was not being asked to account for her whereabouts. Jane is an example of a survivor who has not yet been able to extract herself entirely from a violent relationship, but was involved in a qualitative study of her experiences that did not place her in jeopardy. It is argued here, therefore, that the (ex-) partners of various types of perpetrators can be interviewed, if sufficient care is taken, and, in the interests of obtaining a representative data sample, it is important not to limit study participants to those who are entirely free from the risk of further violence.

Following the 'change in partner-violent men' study the researcher would agree that qualitative interviews can, and do, affect study participants. Potential negative effects must be considered. The potential bias created by an over-cautious approach to recruitment must also be considered. In the main, study participants appeared positive about the opportunity to take part in this study. All study participants were phoned the day following their interview (survivors were phoned by their advocacy worker) and none of them expressed any regret about taking part. However, this is anecdotal evidence, and the need for more objective research, with interviewees, about the effects of research participation remains.

\section{Case study 3: School-based research on interpersonal violence and abuse}

This final case study is based on two multi-method school-based European research projects on IPVA within adolescent (aged 14-17 year-old) relationships. In total, the research projects took place in over 50 schools, comprising of two separate surveys of more than 6000 young people, and 180 interviews. The first study (Barter et al 2009), undertaken in the UK, explored the use of emotional, physical and sexual forms of violence in adolescent relationships. The second project (Barter et al 2015) 
addressed the emerging issue of abuse through new technologies, including controlling behaviours and pressured sexting across five European countries. Both studies facilitated young people's participation through youth advisory groups.

Any research on IPVA requires careful consideration, especially when children and young people are involved. However, in line with Article 12 of the Convention of the Rights of the Child, we recognise the importance of understanding young people's lives from their perspectives and listening to their voices. In interviews with young people we repeatedly heard how their relationships and associated problems often failed to be recognised or taken seriously. Consequently, the ethical question is not whether we should undertake IPVA research with children and young people but how to undertake it so no harm is caused.

The methodological and conceptual issues relating to the research have already been discussed (see Barter, 2014). This casestudy will build on this to explore the ethical issues associated with researching IPVA in western school contexts, focusing on reducing stigmatisation, identification, and risk in the fieldwork setting. The well-rehearsed arguments regarding the importance of securing consent from young people and gatekeepers - including parents -to research participation in schools will not be repeated here (see Jason 2011). To outline briefly, both projects required young people to provide informed written consent to participate. Parental consent was more complex and largely depended on the research tradition in each country. Within the UK, opt-out or passive parental consent was deemed acceptable as school gatekeepers had already provided consent: if parents/carers did not want their child to participate they were required to return a form via a stamped addressed envelope or email. In a number of other countries opt-in active parental consent was required.

Participants and parents/carers received information outlining the aims of the research, confidentiality, anonymity and rights of young people within the research process. Given the sensitivity of the research, the wording of the information required careful consideration. It was imperative that the terminology used did not place young people at additional risk. Terms such as abuse and violence are not only heavily value laden (Stanko, 2003) but could potentially lead to negative repercussions if a violent or controlling partner became aware of the material. Clearly information should not be misleading or lessen the sensitivity of the issues under investigation. However, we needed to ensure that our research would not cause any harm to potential participants. Reflecting the youth advisory group discussions and piloting we decided to use the term 'concerns with young people's relationships' to explain the research topic. It was felt this accurately described the study's focus but was also sufficiently wide-ranging that abusive partners would not feel overly threatened or defensive.

In order to minimise potential stigmatisation, the information provided made it clear that the research sought to explore the views of all young people irrespective of their intimate relationship experiences. Although only participants who reported an intimate partner answered all the survey questions, a number of sections required completion by all participants. Discussions with young people prior to the research underlined the importance of emphasising the universal basis of the study for a range of reasons:

1. Parents may not be aware of their child's relationships and young people stressed the importance of maintaining this situation. In some schools both gatekeepers and parents stated that young people were rarely in relationships. However, the survey data contradicted these assumptions showing that in nearly all schools the majority of participants reported a relationship experience.

2. It was felt that some parents, especially those who used an authoritative or controlling parenting style, may react negatively if they suspected their child of concealing a relationship and consequently may question their wish to participate.

3. Some parents, due to cultural, religious or moral reasons, may not condone young peoples' intimate relationships. However, this does not necessarily mean their children share these beliefs. It was therefore important that these relationships were not discovered. In interviews with some young women, especially those from South Asian 
communities, participants spoke about possible reprisals including 'honour-based' violence and forced marriage if their families or wider communities found out about their relationships (Barter at al 2009). The emphasis on all young people's views and the focus on 'concerns' (which could include concerns around the acceptability of non-marital intimate relationships) meant parents were less likely to interrogate their child's wish to participate.

When undertaking classroom-based surveys on IPVA careful consideration is required in relation to managing peer-group dynamics. This is especially important in light of the gendered double-standard of sexual reputations prevalent across many cultures. Within the classroom context, this double-standard is monitored and policed through peer-group surveillance of young people's behaviour. Young women are required to protect their sexual morality or risk being labelled a 'slut' while young men are required to demonstrate an active sexual prowess; to be a 'stud'. To manage these dynamics it was optimal to have two researchers in each classroom, although this was not always possible. This ratio enabled researchers to monitor confidentiality by ensuring pupils were not observing each other's responses and also allowed researchers to support those who required additional assistance. With a single researcher, teachers were more inclined to 'patrol' the classroom: clearly not conducive to maintaining confidentiality. Indeed some teachers required greater management than participants.

On average the survey took 25 minutes to complete. However, participants with no relationship experiences finished much sooner. This meant young people could potentially be identified and possibly stigmatised for not having a relationship; especially pertinent for boys who may feel pressured to present themselves as sexually experienced. Also participants who completed early may disrupt the class or observe other pupil's responses. In addition, we needed to ensure that pupils who did not want to take part, or whose parents refused consent, could not be easily identified. In response to these challenges a 'fun' quiz was included at the end of the survey to keep participants occupied. The quiz was provided separately for those who were not participating thus reducing possible identification. The quiz also enabled young people who took longer to complete the survey, often those who had multiple IPVA experience, to do so without being observed as attention was diverted elsewhere. The quiz also provided a safety mechanism to reduce possible surveillance of young people whose families and wider communities, including classroom peers, may not condone relationships as it was difficult to determine if participants were answering the survey or the quiz questions.

In some classes we also asked teachers to answer the quiz questions. This helped to keep teachers occupied and therefore provided greater confidentiality to pupils. A researcher then asked the teachers to answer the questions the end of the session, which the class often found greatly entertaining. This activity also provided a useful diversion and a safe space for participants who may be unsettled to compose themselves unobserved by their peers, supported by researchers if necessary. At the end of the survey all participants were provided with information on national and local help services for young people. It was compulsory for all young people to take the information to ensure those who needed it were not identified.

Ethical considerations associated with recruiting young people with IPVA experiences for the interview sample were considerable. It was clear that the classroom context was not a conducive, or necessarily a safe, environment for young people to volunteer to participate in the interview stage. Wider fieldwork strategies to combat stigmatisation, identification and in some instances risks, were required. We used multiple strategies to engage with young people including accessing through specific young people's projects, school pastoral services and also via the survey sample; researchers administering the survey observed participants to identify those who seemed particularly engaged with the activity. Towards the end of the survey when the class attention was diverted by the quiz the researchers would ask small groups of young people, including the identified participant, if they would like to take part in the interview stage of the research. This apparently random selection procedure safeguarded against peer identification and stigmatisation. In the subsequent interviews it was confirmed that this process had been successful as it enabled young people to volunteer without feeling worried about peer reactions.

An obvious implication of this selection process was that some young people who had not experienced a relationship or had no IPVA experiences were also invited to be interviewed. To compensate, we developed - with the youth advisory groups - a 
number of vignettes depicting different aspects of relationships problems, which young people were asked to comment on; this enabled participants with no personal experiences to contribute and young people didn't feel we had wasted their time (Barter and Renold, 2000). Interestingly, in some instances although young people initially stated they had no relationship concerns, in the subsequent discussions it became clear that they were experiencing some level of control and surveillance, reflecting the normalisation of abuse within intimate relationships.

Some research teams provided vouchers to thank interview participants for taking part. The use of vouchers for research remains contentious (Alderson, and Morrow, 2011). Although widely used and ethically accepted in many countries, including the UK, this was not reflected across all country contexts. In some of the European countries, vouchers were deemed ethically problematic representing too great an incentive which may override young peoples' reservations and concerns. Obviously, any undue influence is not acceptable as participation should be undertaken voluntarily, free from pressure, and should not cause emotional harm (Alderson \& Morrow, 2011). However, in many countries it is recognised that the time and effort involved in research participation should be acknowledged. The amount (f10) was not deemed by the youth advisory groups or in the pilot stage as being sufficient to override reservations. Indeed, we had numerous young people who declined to participate despite the voucher, indicating the amount was proportionate in an English context.

In addition, the voucher provided an excuse for young people to explain their involvement to peers: 'I'm only doing it for the money' (Barter et al 2004). In this way it represented an important tool to combat peer pressure and to decrease identification and possible stigmatisation. Young interview participants said the voucher did not influence their decision but was a helpful mechanism to explain their participation to peers and, in some instances, partners.

\section{Discussion: benefitting from research and mitigating risk}

The case studies and discussion presented in this paper add to a growing literature on the governance of social research exploring IPV - including the abuse of children and working within refugee settings, and the associated principles of minimising 'harm', negotiating 'informed consent', data protection, confidentiality and anonymity (for example, see ethical discussion in Barter et al., 2015; Hynes, 2003; Radford et al., 2013 and McGinn et al. 2015). All social research can present possible benefit(s) or risk(s) to participants; this is particularly relevant for necessary research on IPV where risks, if not well managed, can be especially damaging. The case studies presented clearly show that possible risks can be effectively addressed and managed through the careful consideration of three key areas, discussed below: (1) skills of the research team; (2) ways of accessing and recruiting participants; and, (3) the appropriate use of data.

Before moving to a discussion of the management of possible risk in research on IPV, it is important to reflect on the possible benefits that involvement in such research can bring to both survivors and perpetrators. Qualitative interviews - the cornerstone of many social research studies exploring IPV - have been discussed as a positive intervention by previous researchers (Scerri, Abela, \& Vetere, 2012). Griffin, Resick, Waldrop, and Mechanic (2003) investigated the effects of taking part in interviews among domestic violence survivors and found that the vast majority bore no ill effects from the experience, and most described it as a positive experience. Johnson and Benight (2003); Newman, Walker, and Gefland (1999); and Walker, Newman, Koss, and Bernstein (1997) report similar results from similar studies. In agreement with Scerri et al. (2012), the case studies presented here suggest that skilfully conducted qualitative interviews can be, and often are, a positive intervention in the lives of study participants; they give study participants an opportunity to off-load and to obtain the benefits of talking through their thoughts with an empathetic other. Future research should incorporate rigorous investigation of this suggested benefit as these reported benefits are often collected through informal, ad-hoc follow-up conversations. 


\section{Skills of the research team}

Scerri et al. (2012, p. 102) argues that "to act ethically and understand some of the complexity of the interaction between researcher and participants" clinical expertise or training may be necessary; it is argued here that researchers in this field should have had the benefit of properly supervised clinical practice in this area. The case studies presented clearly indicate the importance of ensuring that both researcher and (where appropriate) interpreter have acquired relevant experience in order to ethically manage challenging topics and conversations.

Implications of cross-language research have been explored and it is recognised that the boundaries of insider-outsider research are not easily drawn (Temple and Young, 2004; Temple and Moran, 2006; and Temple, 2002, 2004). If the presence of a translator is acknowledged beyond the current practice of being "ghostwriters - there, but generally unacknowledged" (Temple, 2004:846) then the advantages and disadvantages of insider and outsider research apply. It cannot be assumed that speaking the same language constitutes being of the same 'community'. Time needs to be allocated for the 'insiders' of the 'community' (the interviewee and the translator) to speak to each other to go through details such as which area of the country of origin they originate from, the date they left, their political affiliations, religion and other ways of knowing each other in order that some sense of trust in each other can form. An 'outsider' may not need this time and process but will need other strategies to gain trust and rapport. Having an interpreter who is an 'insider' within a given 'community' adds complexity around the requirement for confidentiality - both at the time of the interview and on an on-going basis. Sensitive disclosures of abuse may require on-going support and, without the availability of therapeutic interventions, that support may come from the same 'community' interviewees live within. When interviewing participants, any limits to confidentiality will need to be clear, as will the dangers around breaching confidentiality. Ensuring interpreters fully adhere to the principle of confidentiality is paramount in contexts where known political affiliations are risky.

\section{Ways of accessing and recruiting participants}

Critical to all research investigating IPV are ways of accessing, identifying, inviting and recruiting participants. Often relying on engagement with local stakeholders and gatekeepers, access to potential participants and their subsequent recruitment can be challenging. A research strategy of multiple gatekeepers is theoretically useful but in practice may be impractical as access to participants 'with and through gatekeepers' requires the adoption of a 'flexible' (Bloch, 1999) approach to fieldwork. Gatekeepers may themselves need to be trusted by the populations involved and client confidentiality will have been part of this. If the research is not in the interests of gatekeepers, support or access may be denied which, in contexts of conflict or insecurity, may end interview possibilities altogether.

Linked to this is the key imperative of obtaining informed consent - often presented as being key to ethically-sound research. Processes of obtaining consent are, often, fraught with complexities associated with power: gatekeepers, stakeholders, researchers, interpreters and the anticipation of benefit to participation - or negative consequences of non-participation can, and do, influence decisions to participate in research. Linked to this is the need to balance concerns of the researcher and possibly other actors - about possible negative consequences of participation surrounding an individuals' choice to participate in IPV research. Case study 2 reflects on the importance of balancing this risk; the individual (in this case, an IPV survivor still in contact with her perpetrator) makes a decision to participate after being informed about the study, and the researcher makes a judgement call - based on his own experience and skill in working in the field of IPV research - about how best to support and protect her participation in the study. 


\section{The appropriate use of data}

Considerations of the appropriate use of data involve informed assurances of maintaining the confidentiality and anonymity of participants. This is particularly important in relation to possible peer-group dynamics associated with possible shame and stigma associated with status as a survivor, or perpetrator, of IPV.

In some contexts, the liberal value of privacy - or the right to a private life - is not a norm and this principle does not easily blend into standard research practices. For example, the debate about Western individualistic versus Asian collectivistic values - as related to the first case study - whilst beyond the scope of this contribution is worth noting (for a discussion of the concept of privacy and its meaning in Thailand see Kitiyadisai, 2005). This can present challenges to researchers: how to protect participants where such privacy is not considered relevant or important? How to develop mechanisms that allow for confidentiality and anonymity when access to and engagement with participants is mediated by a possibly unsupportive gatekeeper or interpreter?

Such contextually-specific sensitivities to collecting data relate closely to trust and mistrust. Who to trust and who to mistrust in humanitarian contexts - such as outlined in case study 1 - when disclosing abuse is complex and there are a number of caveats and considerations researchers need to make in such instances, including understanding ambiguities of conducting such research and strategies to build trust (Hynes, 2003). In humanitarian contexts, disclosing abuse and/or exploitation has added complexities given disruption of any existing community sanctions against sexual violence, environments of impunity and threat of violence from a range of potential perpetrators including, in recent years, humanitarian workers. As a result, ensuring anonymity with data from conflict or humanitarian settings requires more than the use of pseudonyms as inadvertently identifying individuals may risk lives. Beyond the use of pseudonyms, defining characteristics of age, ethnicity, religion, language or dialect spoken each require consideration. Naming refugee camps, sizes or location also requires deliberation. Anonymity needs to be assured to avoid real risks and harm to individuals living in contexts of uncertainty. Use of data can be potentially stigmatising and avoidance of this is an overriding consideration.

These challenges exist outside of humanitarian contexts, as case studies 2 and 3 outline. Finding ways to protect the identity of participants, particularly where admitting to having experienced IPV could have great social consequences, is key. Case study 3 outlines innovative approaches to ensuring that school learners who had experienced IPV could not be distinguished from those who had not; such contextually sensitive and adaptable methods provide good practice examples of how to navigate the complexities of researching IPV at a population level.

\section{Conclusion}

The case studies presented in this paper highlight that special attention is required when conducting research with survivors and perpetrators of IPV. International guidelines and best practice examples are increasing in number (e.g. Refugee Studies Centre, 2007; Mackenzie et al., 2007; Child Protection Monitoring and Evaluation Reference Group, 2012; Graham et al., 2013; Zimmerman and Watts, 2003) and we would urge more researchers to publish reflections on their ethical challenges and solutions. Moving forward, researchers are encouraged to embed methodological questions related to agency, vulnerability and power in processes of recruitment and obtaining consent within studies exploring IPV (Hurst 2008; Lott, 2005). 


\section{References}

Alderson, P. (2014) Ethics of research with children. In O. Saracho (ed) Handbook of Research Methods in Early Childhood Education. Charlotte, North Carolina: Information Age Publishing Inc.

Alderson, P. and Morrow, V. (2011) The Ethics of Research with Children and Young People: A Practical Handbook, London; Sage.

Apple, B., (1998), School for Rape: The Burmese Military and Sexual Violence, Earthrights International, United States

Barter, C. (2014) Researching young people's experiences of intimate partner violence: Concepts, contexts and consequences, pp. 33-49, in Aghtaie, N. and Gangoli, G. (Eds) Understanding Gender Based Violence, National and International Contexts. London; Routledge.

Barter, C., McCarry, M., Berridge, D. and Evans, K. (2009) Partner Exploitation and Violence in Teenage Intimate Relationships, London, NSPCC.

Barter, C. and Renold, E. (2000) "I wanna tell you a story": The application of vignettes in qualitative research with young people', Social Research Methodology, Theory and Practice, 3 (4), 307-323.

Barter, C., Renold, E., Berridge, D. and Cawson, P. (2004) Peer Violence in Children's Residential Care. Basingstoke: Palgrave, Macmillan

Barter, C., Stanley, N., Wood, M., Aghtaie, N., Larkins, C., Øverlien, C. and Lesta, S. et al (2015). Safeguarding Teenage Intimate Relationships (STIR): Connecting online and offline contexts and risks. Research Report (Retrieved 27/10/15 from: http://stiritup.eu/wpcontent/uploads/2015/06/STIR-Exec-Summary-English.pdf).

Bloch, A. (1999) Carrying Out a Survey of Refugees: Some Methodological Considerations and Guidelines, Journal of Refugee Studies, $12 / 4$.

Child Protection Monitoring and Evaluation Reference Group, (2012), Ethical Principles, Dilemmas and Risks in Collecting Data on Violence Against Children: A Review of Available Literature, UNICEF: New York

Esterhuizen, L. (2004) Doing Case Studies for the Refugee Sector: A DIY Handbook for Agencies and Practitioners, London: Information Centre about Asylum and Refugees in the UK (ICAR).

Fontes, L. A. (2004). Ethics in violence against women research: The sensitive, the dangerous, and the overlooked. Ethics \& Behavior, 14(2), 141-174.

Graham, A., Powell, M., Taylor, N., Anderson, D. and R. Fitzgerald, (2013), Ethical Research Involving Children, Innocenti, UNICEF: Florence; see also http://childethics.com/ - a joint initiative between UNICEF and ChildWatch - for further resources and guidelines.

Griffin, M. G., Resick, P. A., Waldrop, A. E., \& Mechanic, M. B. (2003). Participation in trauma research: Is there evidence of harm? Journal of Traumatic Stress, 16(3), 221-227.

Hilhorst, D. and Jansen, B.J., (2012), Constructing Rights and Wrongs in Humanitarian Action: Contributions from a Sociology of Praxis, in Hynes, P., Lamb, M., Short, D. and Waites, M., (Eds.), Sociology, Vol.46, No.5, p.891-905. 
Human Rights Watch (2012) Ad hoc and Inadequate: Thailand's Treatment of Refugees and Asylum Seekers, New York: Human Rights Watch.

Hurst, S.A. (2008). Vulnerability in research and health care; Describing the elephant in the room? Bioethics, 22(4), 191-202.

Hynes, T. (2003) The Issue of 'Trust' or 'Mistrust' in Research with Refugees: Choices, Caveats and Considerations for Researchers, Working Paper No.98, Geneva: United Nations High Commissioner for Refugees.

Hynes, P., (2010), Global Points of 'Vulnerability': Understanding the Processes of the Trafficking of Children into, within and out of the UK, International Journal of Human Rights, Vol.14, No.6, p.949-967

Jason, L.A., Pokorny, S. and Katz, R. (2001). Passive Versus Active Consent: A Case Study in School Settings. Journal of Community Psychology, 29(1), 53-68.

Johnson, L. E., \& Benight, C. C. (2003). Effects of trauma-focused research on recent domestic violence survivors. Journal of Traumatic Stress, 16(6), 567-571.

Karen Human Rights Group (KHRG), (2006), Dignity in the Shadow of Oppression: The Abuse and Agency of Karen Women under Militarisation, KHRG, Thailand

Kitiyadisai, K. (2005), Privacy rights and protection: foreign values in modern Thai context, Ethics and Information Technology, Vol.7, p.17-26.

Krug, E.G., Dahlber, L.L., Mercy, J.A., Zwi, A.B. and Lozano, R. (2002) World Report on Violence and Health, Geneva: WHO.

Lott, J.P. (2005). Module Three: Vulnerable/Special participant populations. Developing World Bioethics, 5(1), 30-54.

Mackenzie, C., McDowell, C. and E. Pittaway, (2007), Beyond 'Do No Harm': The Challenge of Constructing Ethical Relationships in Refugee Research, Journal of Refugee Studies, Vol.20, No.2, p.299-319.

McCosker, H., Barnard, A., \& Gerber, R. (2001). Undertaking sensitive research: Issues and strategies for meeting the safety needs of all participants. Paper presented at the Forum Qualitative Sozialforschung/Forum: Qualitative Social Research.

McGinn, T., Taylor, B., McColgan, M. \& McQuilkan, J. (2014). Social Work Literature Searching: Current Issues With Databases and Online Search Engines. Research on Social Work Practice [Online]. Available:

http://rsw.sagepub.com/content/early/2014/09/17/1049731514549423.abstract [Accessed September 21, 2014].

McGinn, T., Taylor, B., McColgan, M., \& Lagdon, S. (2015). Survivor Perspectives on IPV Perpetrator Interventions A Systematic Narrative Review. Trauma, Violence, \& Abuse. DOI: 10.1177/1524838015584358

McGinn, T. (2016). Types of change in partner-violent men: insights from a qualitative study of survivor and perpetrator perspectives. Manuscript submitted for publication.

McGinn, T. (2016). A systematic synthesis, of qualitative studies, of partner-violent men's views on intervention and change. Submitted for publication.

Newman, E., Walker, E. A., \& Gefland, A. (1999). Assessing the ethical costs and benefits of trauma-focused research. General Hospital Psychiatry, 21(3), 187-196. 
Radford, L., Corral, S., Bradley, C., Fisher, H., Bassett, C., Howat, N. and S. Collishaw, (2011) Child Abuse and Neglect in the UK Today, NSPCC, London.

Refugee Studies Centre, (2007), Ethical Guidelines for Good Research Practice, Refugee Survey Quarterly, Vol.24, Issue 3, DOI:10.1093/rsq/hdi0250

Scerri, C. S., Abela, A., \& Vetere, A. (2012). Ethical dilemmas of a clinician/researcher interviewing women who have grown up in a family where there was domestic violence. International journal of qualitative methods, 11(2), 102-131.

Shan Women's Action Network (SWAN) and the Shan Human Rights Foundation (SHRF), (2002), License to Rape: The Burmese Military Regime's Use of Sexual Violence in the Ongoing War in Shan State, SWAN and SHRF, Thailand.

Shaw, C., Brady, L. and Davey, C. (2011) Guidelines for Research with Children and Young People, National Children's Bureau.

Stanko, E.A. (2003). Introduction: Conceptualizing the meaning of violence. In E.A. Stanko (Ed.), The Meanings of Violence (pp. 1-13). London: Routledge.

Sullivan, C. M., \& Cain, D. (2004). Ethical and safety considerations when obtaining information from or about battered women for research purposes. Journal of Interpersonal Violence, 19(5), 603-618.

Temple, B., (2002), Crossed Wires: Interpreters, Translators and Bilingual Workers in Cross-language Research, Qualitative Health Research, Vol.12, No.6, p.844-854

Temple, B., (2004), Ghost Writers: Using Biographical Methods Across Languages, in Chamberlayne, P. et al. (eds.), Biographical Methods and Professional Practice, Policy Press, London

Temple, B. and R. Moran, (2006), Doing Research with Refugees, Policy Press, Bristol.

Temple, B. and A. Young, (2004), Qualitative Research and Translation Dilemmas, Qualitative Research, Vol.4, No.2, p.161-178

Walker, E. A., Newman, E., Koss, M., \& Bernstein, D. (1997). Does the study of victimization revictimize the victims? General Hospital Psychiatry, 19(6), 403-410

WHO, (2010), Preventing Intimate Partner and Sexual Violence Against Women: Taking Action and Generating Evidence, Geneva: WHO.

Zimmerman, C. and C. Watts, (2003), WHO Ethical and Safety Recommendations for Interviewing Trafficked Women, World Health Organisation and London School of Hygiene and Tropical Medicine: London. 